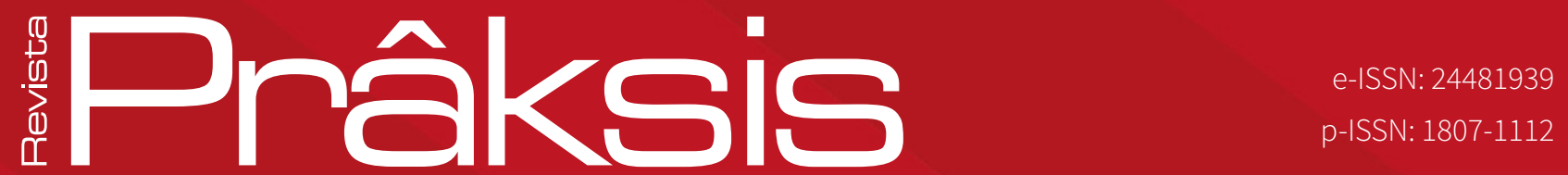

Recebido em: 11 de fevereiro de 2018

Aprovado em: 20 de junho de 2018

Sistema de Avaliação: Double Blind Review

RPR |a. 15 |n. 2 |p. 173-194 | jul./dez. 2018

DOI: https://doi.org/10.25112/rpr.v2i0.1565

\title{
A PESSOA COM dEFICIÊNCIA NA política pÚBlica do pROGRAma NACIONAL DE ACESSO AO ENSINO TÉCNICO E EMPREGO (PRONATEC) VIVER SEM LIMITE)
}

THE PERSON WITH DISABILITIES IN THE PUBLIC POLICY OF THE NATIONAL PROGRAM OF ACCESS TO TECHNICAL EDUCATION AND EMPLOYMENT (PRONATEC / LIVING WITHOUT LIMIT)

\section{Emerson Tyrone Mattje}

Doutor em Diversidade Cultural e Inclusão Social (Universidade Feevale/Brasil).

Professor na Universidade do Vale do Rio dos Sinos (São Leopoldo/Brasil).

E-mail: mattje@feevale.br.

\section{Everton Rodrigo Santos}

Doutor em Ciência Política (Universidade Federal do Rio Grande do Sul/Brasil).

Professor na Universidade Luterana do Brasil (Canoas/Brasil).

E-mail: evertons@feevale.br. 


\section{RESUMO}

O objetivo central deste artigo é analisar a política pública (Pronatec/Viver sem Limite) instituída pelo governo federal, especificamente, em relação aos municípios de Canoas, Estância Velha, Novo Hamburgo, Porto Alegre e São Leopoldo, no período de 17/11/2011 a 31/12/2015, que tem como finalidade a qualificação profissional das pessoas com deficiência, por meio das ações de educação profissional e tecnológica desenvolvidas no âmbito do Pronatec, observadas as condições de acessibilidade e participação plena. Nesse sentido, pretende-se demonstrar a hipótese de que, muito embora a deficiência possa se apresentar na modalidade física, visual, mental, auditiva e intelectual, a maioria das pessoas com deficiência matriculadas no Pronatec/Viver sem Limite apresentam deficiência física, em virtude da maior e mais fácil adaptabilidade da empresa a este tipo de deficiência do que do deficiente à empresa. Este argumento estando correto, subverte, se não limita, a concepção inicial desta política pública. A metodologia utilizada é qualitativa, ou seja, constituiu-se na análise documental da legislação pertinente ao tema, bem como, na análise da política pública do Pronatec/Viver sem Limite, instituído por meio da Lei $n^{\circ}$ 12.513/2011 e regulamentado pelo Decreto $n^{\circ}$ 7.612/2011 (BRASIL, 2011). Utilizamos, também, entrevistas semi-estruturadas com os destinatários das políticas públicas, ou seja, as noventa e duas pessoas com deficiência matriculadas nos cursos de qualificação profissional do Pronatec/Viver sem Limite, nos municípios de Canoas, Estância Velha, Novo Hamburgo, Porto Alegre e São Leopoldo, no período de 17/11/2011 a 31/12/2015.

Palavras-chave: Pessoa com deficiência. Política pública. Inclusão social.

\section{ABSTRACT}

The main objective of this article is to analyze the public policy (Pronatec / Living without Limit) established by the federal government specifically, in relation to the municipalities of Canoas, Estância Velha, Novo Hamburgo, Porto Alegre and São Leopoldo, in the period from 11/17/2011 to 12/31/2015, whose purpose is the professional qualification of people with disabilities, through the professional and technological education actions developed within Pronatec, observing the conditions of accessibility and full participation. In this sense, it is intended to demonstrate the hypothesis that although the deficiency may present in the physical, visual, mental, auditory and intellectual modality, most people with disabilities enrolled in Pronatec / Living without Limit are physically handicapped due to the company's greater and easier adaptability to this type of disability than to the disabled person. This argument being correct, subverts, if not limited, the initial conception of this public policy. The methodology used is qualitative, that is, it consisted of documentary analysis of legislation relevant to the topic, as well as, in the analysis of the public policy of Pronatec / Living without Limit, established through Law 12,513 / 2011 and regulated by Decree 7,612 / 2011 (BRAZIL, 2011). We also used semi-structured interviews with public policy recipients, that is, the ninety-two persons with disabilities enrolled in the Pronatec / Living without Limit professional qualification courses in the municipalities of Canoas, Estância Velha, Novo Hamburgo, Porto Alegre and São Leopoldo, in the period from $11 / 17 / 2011$ to $12 / 31 / 2015$.

Keywords: Disabled person. Public policy. Social inclusion. 


\section{INTRODUÇÃO}

As indefinições que norteiam o conceito de pessoa com deficiência dificultam a efetiva inclusão dessas pessoas na escola, nos espaços de lazer, bem como, no mundo do trabalho. 0 trabalho que as pessoas com deficiência realizam é uma forma de valorização e de capacitação para gerenciarem a sua própria sobrevivência. A oportunidade laborativa é um meio de mostrar que sujeitos com deficiência podem contribuir muito para o crescimento econômico do País, independentemente de seus impedimentos de diferentes ordens. Sob esse prisma, é fundamental explicitar de maneira clara tal conceito.

Outrossim, na atualidade, as empresas têm requisitado pessoas com maior nivel de motivação e novas habilidades para o exercício de suas atividades.

Dessa forma, percebe-se que incluir pessoas com deficiência no ambiente de trabalho é uma tarefa complexa. Essa complexidade também se dá pelo fato de que as pessoas com deficiência, muitas vezes, são excluídas do mercado de trabalho por falta de reabilitação profissional, de meios de transporte, de apoio das próprias famílias, de escolaridade e de qualificação para a função.

Por conseguinte, a qualificação profissional deve oferecer à pessoa com deficiência a possibilidade de mediar suas relações com e no mundo, a fim de que o trabalho se constitua em uma via de inclusão social e de cidadania. Nesse aspecto, o Programa Nacional de Acesso ao Ensino Técnico e Emprego (Pronatec/ Viver sem Limite), instituído por meio da Lei no $12.513 / 2011$ e regulamentado pelo Decreto n 7.612/2011 (BRASIL, 2011), é uma política pública que tem por finalidade a qualificação profissional das pessoas com deficiência, por meio das ações de educação profissional e tecnológica desenvolvidas no âmbito do Pronatec, observadas as condições de acessibilidade e participação plena, tais como adequação de equipamentos, de materiais pedagógicos, de currículos e de estrutura física.

0 presente artigo tem como problema central de pesquisa entender quais são as modalidades de deficiência abrangidas pelos matriculados no Pronatec/Viver sem Limite. Assim, o objetivo deste artigo é analisar essa política pública, ou seja, o Pronatec/Viver sem Limite, instituído pelo governo federal, especificamente, em relação aos municípios de Canoas, Estância Velha, Novo Hamburgo, Porto Alegre e São Leopoldo, no período de 17/11/2011 a 31/12/2015.

No primeiro tópico, "O conceito de deficiência ao longo do tempo", demonstrar-se-á que para identificar as pessoas com deficiência é comum, em palestras e em conversas informais, o uso da expressão "pessoas com necessidades especiais" e/ou "pessoas portadoras de necessidades especiais", como forma de evitar o uso da palavra "deficiência".

Porém, a expressão "necessidades especiais" não deve ser utilizada como sinônimo de deficiência (intelectual, auditiva, visual, física ou múltipla), pois uma pessoa com insuficiência orgânica ou dificuldades de aprendizagem possui necessidades especiais, mas não é considerada pessoa com deficiência. 
Verificar-se-á que, no Brasil, até pouco tempo, a utilização de termos como "aleijados", "incapazes", "inválidos" indicava que a sociedade brasileira encarava essas pessoas como inúteis e sem valor.

Demonstrar-se-á também que ao longo dos anos existiram diversos conceitos para definir pessoa com deficiência, e que os impedimentos físicos, mentais, intelectuais e sensoriais passaram a ser considerados características das pessoas, inerentes à diversidade humana.

Nessa parte serão utilizados, de forma preponderante, os seguintes autores: Bernardes; Araújo (2012), Amiralian et al. (2000), Marta (2013), Boucinhas Filho (2005) e Diniz; Squinca; Medeiros (2007).

No segundo tópico, "Políticas públicas de proteção às pessoas com deficiência e o Pronatec/Viver sem Limite", conceitua-se políticas públicas, bem como, analisa-se o Programa Nacional de Acesso ao Ensino Técnico e Emprego (Pronatec/Viver sem Limite), realiza-se uma abordagem demográfica dos entrevistados e seus respectivos municípios e aborda-se a caracterização das deficiências encontradas, remetendo-se à deficiência física, visual, mental auditiva e intelectual, pretendendo-se demonstrar a hipótese de que, muito embora a deficiência possa se apresentar na modalidade física, visual, mental, auditiva e intelectual, a maioria das pessoas com deficiência matriculadas no Programa Nacional de Acesso ao Ensino Técnico e Emprego (Pronatec/Viver sem Limite) apresentam deficiência física, em virtude da maior e mais fácil adaptabilidade da empresa a este tipo de deficiência do que do deficiente à empresa. Este argumento estando correto, subverte, se não limita, a concepção inicial desta política pública.

Este artigo justifica-se sob o argumento de que abrange uma questão de extrema relevância social, uma vez que analisa uma política pública voltada à qualificação profissional das pessoas com deficiência e, por conseguinte, à inclusão plena dessas pessoas na sociedade. Por outro lado, academicamente, este artigo vem somar-se a parca bibliografia sobre políticas públicas que avaliam a política sob o ângulo dos destinatários, seu maior beneficiário.

A metodologia da pesquisa é qualitativa, pois se constituiu na análise documental da legislação pertinente ao tema (Convenção Internacional sobre os Direitos das Pessoas com Deficiência, Constituição Federal, leis, decretos e demais normas jurídicas), bem como, na análise da política pública do Pronatec/ Viver sem Limite.

Além disso, utilizamos entrevistas semi-estruturadas com os destinatários das políticas públicas, ou seja, as noventa e duas pessoas com deficiência matriculadas nos cursos de qualificação profissional do Programa Nacional de Acesso ao Ensino Técnico e Emprego (Pronatec/Viver sem Limite), nos municípios de Canoas, Estância Velha, Novo Hamburgo, Porto Alegre e São Leopoldo, no período de 17/11/2011 a 31/12/2015. 
A coleta de dados foi realizada entre os dias 24 de outubro até 3 de novembro de 2016 pelo Núcleo de Pesquisa e Estatística (NUPE) da Universidade Feevale.

\section{CONCEITO DE DEFICIÊNCIA AO LONGO DO TEMPO}

No âmbito mundial, mais precisamente no século XVIII, surgiram os primeiros indícios de preocupação, por parte dos profissionais da área da saúde, em criar uma classificação das doenças. Mas, somente a partir de 1948, por meio da VI Revisão da Classificação Internacional de Doenças (CID-6), referenciou-se o rol de doenças crônicas que necessitariam de maior atenção (AMIRALIAN et al., 2000).

Cabe salientar que a abordagem da deficiência, segundo o modelo médico, toma como ponto de partida a realidade biológica do comprometimento. Por conseguinte, a deficiência é um atributo ou uma característica do indivíduo causada diretamente por doença, trauma ou outra condição de saúde, que requer algum tipo de intervenção de profissionais para "corrigir" ou "compensar" o problema (BERNARDES; ARAÚJO, 2012).

No que se refere ao entendimento do termo pessoas deficientes, surgiu a Declaração dos Direitos das Pessoas Deficientes, aprovada pela Assembleia Geral da Organização das Nações Unidas, em 9 de dezembro de 1975, que proclamou, em seu artigo I: "O termo 'pessoas deficientes' refere-se a qualquer pessoa incapaz de assegurar por si mesma, total ou parcialmente, as necessidades de uma vida individual ou social normal, em decorrência de uma deficiência congênita ou não de suas faculdades físicas ou mentais".

Em 1976, na IX Assembleia da Organização Mundial da Saúde (OMS), surgiu uma nova conceituação, a Classificação Internacional de Deficiências, Incapacidades e Desvantagens (CIDID), que vinha sendo utilizada pelos países-membros da ONU para determinar a prevalência das incapacidades. Essa determinação era aproveitada em diversas áreas, por exemplo, na saúde ocupacional, para concessões de benefícios, como forma de avaliação em pacientes em fase de reabilitação, etc. Mediante a terminologia empregada pela CIDID, seria possivel compreender o grau de limitação do indivíduo (AMIRALIAN et al., 2000).

Nesse contexto, o conceito de deficiência apresentado pela CIDID, na época, propunha uma denominação a ser aplicada de forma universal, por meio de escala por nivelamento de dependência e limitação, sendo elas: a deficiência, a incapacidade e a desvantagem.

A deficiência é toda restrição ou ausência de capacidade para executar uma atividade normalmente, ou dentro da margem do que se considera normal para o ser humano. Nela, o estado patológico está apresentado de forma exteriorizada (BERNARDES; ARAÚJO, 2012). A incapacidade caracteriza o fato de a deficiência restringir as habilidades para desempenhar as tarefas do cotidiano. Nessa categoria, enquadram-se as deficiências de caráter psicológico, físico, sensorial (AMIRALIAN et al., 2000). 
Marta (2010) aponta que, segundo a Organização Mundial da Saúde, a incapacidade resulta de uma situação de desvantagem que limita ou até mesmo impede que uma atividade normal possa ser elaborada (considerando sexo, idade, fatores culturais e sociais). Ademais, está relacionada à interação da pessoa com deficiência e o meio em que vive, restringindo, assim, a participação desta em igualdade de oportunidades com as demais.

A desvantagem trata da deficiência que resulte em prejuízo à pessoa pelo desempenho reduzido de certa função, estando, assim, ligada às dificuldades nas habilidades de sobrevivência (AMIRALIAN et al., 2000).

Um exemplo de pessoas com deficiência que apresentam desvantagens, mas que possuem capacidades, são os hemofílicos e os diabéticos, que, ao receberem o tratamento médico compatível com suas necessidades, podem não desenvolver qualquer tipo de incapacidade, embora estejam em desvantagem acerca das questões alimentares ou do exercício de atividades físicas (AMIRALIAN et al., 2000).

Por meio do entendimento proposto pela CIDID, é possível compreender que uma pessoa pode ter uma deficiência sem incapacidade, uma incapacidade sem desvantagem ou uma desvantagem sem incapacidade ou deficiência. Isso significa dizer que as pessoas com deficiência não devem ser consideradas incapacitadas, uma vez que possuem particularidades que são definidas por intermédio dos conceitos de avaliação do indivíduo. Assim como uma pessoa com deficiência pode apresentar incapacidade e desvantagens para determinadas tarefas, outra pode ser plenamente capaz (AMIRALIAN et al., 2000).

Na legislação brasileira, muitos anos se passaram até que, no dia 24 de outubro de 1989, foi assinada a Lei $n^{\circ}$ 7.853/89 (BRASIL, 1989), que dispôs sobre o apoio e a integração social às pessoas com deficiência. Entretanto, segundo Silva (2006, p. 46), por mais esdrúxulo que possa parecer, a mencionada lei não trouxe qualquer esclarecimento quanto ao termo "pessoa com deficiência".

A ciência entende que os diversos tipos de limitação devem ser enfrentados e solucionados de forma diferenciada, visto que o rol de deficiências não possui classificação homogênea. Deve-se considerar que as limitações de determinada deficiência nem sempre são iguais às de outra, por exemplo, pessoas com deficiência mental ou auditiva não têm as mesmas dificuldades daquelas que apresentam restrições de mobilidade (MARTA, 2013).

A regra geral é que a deficiência é uma consequência de alterações de aptidões classificadas como restrições ou lesões. A grande dificuldade está em rotular quais as variantes de capacidade efuncionalidade que se enquadrariam como deficiências. A solução estaria em listar as alterações de capacidade que devem se enquadrar no rol de deficiências, tornando possível a identificação dos beneficiários (DINIZ; SQUINCA; MEDEIROS, 2007). 
0 artigo 20, § 20, da Lei n 8.742, de 07 de dezembro de 1993 (BRASIL, 1993), em sua redação original, conceituava pessoa com deficiência como sendo "aquela incapacitada para o trabalho e para a vida independente". Todavia, de encontro a essa conceituação, Bublitz (2012, p. 360) concorda com Amiralian et al. (2000) ao defender que deficiência não deve ser confundida com incapacidade (BUBLITZ, 2012, p. 360). Por sua vez, Fávero, da mesma forma, discorda do conceito esboçado na Lei n 8.742, de 07 de dezembro de 1993, ao afirmar que:

Fez muito mal, pois definiu pessoa com deficiência, para efeito deste benefício, como aquela incapacitada para a vida independente e para o trabalho (art. 20, $\S 2^{\circ}$ ). Tal definição choca-se, frontalmente, com todo o movimento mundial pela inclusão da pessoa com deficiência. Num momento em que se procura ressaltar os potenciais e as capacidades da pessoa com deficiência, por esta lei, ela deve demonstrar exatamente 0 contrário. (FÁVERO, 2004 apud SANTOS, 2012, p. 115).

Nesse aspecto, é importante lembrar que, em maio de 2001, a Assembleia Mundial de Saúde endossou uma revisão da classificação terminológica sobre deficiência (BERNARDES; ARAÚJO, 2012). Surgiu, então, a Classificação Internacional de Funcionalidade, Incapacidade e Saúde (BOUCINHAS FILHO, 2005), que visa a fornecer uma perspectiva abrangente, incluindo os planos biológico, pessoal e social das condições de saúde (BERNARDES; ARAÚJO, 2012).

Para a Classificação Internacional de Funcionalidade, Incapacidade e Saúde (CIF), as deficiências são problemas nas funções ou nas estruturas do corpo com um desvio importante ou perda. A inabilidade e a funcionalidade resultam da interação limitada pela saúde da pessoa com o ambiente em que vive (DINIZ; SQUINCA; MEDEIROS, 2007). Dessa forma, percebe-se que a existência de falhas na estruturação ou nas funções do corpo pode resultar em empecilhos para o desempenho de certas atividades. Nesses casos, serão necessárias providências sociais no sentido de tornar possivel a concretização dessas tarefas (BOUCINHAS FILHO, 2005).

No âmbito dos instrumentos jurídicos internacionais, destaca-se a Convenção sobre os Direitos da Pessoa com Deficiência, promulgada pela Organização das Nações Unidas (ONU), aprovada pelo Brasil por intermédio do Decreto Legislativo n 186, de 09 de julho de 2008, com equivalência de Emenda Constitucional, ratificada em $1^{\circ}$ de agosto de 2008 e promulgada pelo Decreto $n^{\circ} 6.949$, de 25 de agosto de 2009, que trouxe ao ordenamento jurídico brasileiro novo conceito de pessoa com deficiência, dessa vez, com status constitucional e, assim, com eficácia revogatória de toda a legislação infraconstitucional que lhe seja contrária.

A mencionada Convenção fez constar em seu preâmbulo que as pessoas com deficiência não podem ser tratadas de forma uniforme, reconhecendo a existência de diversas formas de deficiência, ao afirmar: 
"[...] i) Reconhecendo, ainda, a diversidade das pessoas com deficiência [...]". Cabe frisar que o artigo $1^{\circ}$ da Convenção traz uma nova e importante conceituação de pessoa com deficiência:

O propósito da presente Convenção é promover, proteger e assegurar o exercício pleno e equitativo de todos os direitos humanos e liberdades fundamentais por todas as pessoas com deficiência e promover o respeito pela sua dignidade inerente. Pessoas com deficiência são aquelas que têm impedimentos de longo prazo de natureza física, mental, intelectual ou sensorial, os quais, em interação com diversas barreiras, podem obstruir sua participação plena e efetiva na sociedade em igualdade de condições com as demais pessoas (BRASIL, 2008a).

A Convenção da ONU foi elaborada em processo que contou com a efetiva participação das pessoas com deficiência. Segundo Maia (2013), trata-se de um processo iniciado no final do século XX e início do século XXI, por meio do qual se iniciou a preocupação com a inclusão social das pessoas com deficiência, buscando, para elas, a equiparação de oportunidades após longo período de rejeição e segregação pelo qual passaram.

O núcleo da definição, de acordo com Maia (2013), é a interação dos impedimentos que as pessoas têm com as diversas barreiras sociais, tendo como resultado a obstrução da sua participação plena e efetiva na sociedade, em condição de igualdade com as demais pessoas. Nesse contexto, a deficiência não é mais vista como algo intrínseco à pessoa, como pregavam as definições puramente médicas; a deficiência está na sociedade, não na pessoa.

Os impedimentos físicos, mentais, intelectuais e sensoriais passaram a ser considerados características das pessoas, inerentes à diversidade humana. A deficiência é provocada pela interação dos impedimentos com as barreiras sociais, ou seja, com os diversos fatores culturais, econômicos, tecnológicos, arquitetônicos, etc., de forma a gerar uma impossibilidade de efetiva participação desses sujeitos na sociedade (MARTA, 2013). Por conseguinte, não é a pessoa que apresenta uma deficiência, mas a sociedade. Superar a deficiência não é tão somente cuidar dos impedimentos, mas possibilitar e criar mecanismos que eliminem as barreiras existentes no ambiente.

Salienta-se que a Convenção sobre os Direitos da Pessoa com Deficiência possui, no ordenamento jurídico brasileiro, o status de Emenda Constitucional. Isso significa que todo e qualquer conceito de pessoa com deficiência que contrarie o conceito previsto na mencionada Convenção é entendido como revogado tacitamente. Assim, a legislação brasileira posterior à aprovação da Convenção também deve observá-la.

0 Decreto n 7.612/2011, que institui o Plano Nacional dos Direitos da Pessoa com Deficiência (Viver Sem Limite), também traz a definição de pessoa com deficiência de acordo com Convenção sobre os Direitos da Pessoa com Deficiência, em seu artigo $2^{\circ}$, a saber: 
Art. $2^{\circ}$ - São consideradas pessoas com deficiência aquelas que têm impedimentos de longo prazo de natureza física, mental, intelectual ou sensorial, os quais, em interação com diversas barreiras, podem obstruir sua participação plena e efetiva na sociedade em igualdades de condições com as demais pessoas (BRASIL, 2011).

Mais recentemente, em 6 de julho de 2015, foi promulgada a Lei n 13.146, que institui a Lei Brasileira de Inclusão da Pessoa com Deficiência (Estatuto da Pessoa com Deficiência) e, em seu artigo $2^{\circ}$, dispõe:

Considera-se pessoa com deficiência aquela que tem impedimento de longo prazo de natureza física, mental, intelectual ou sensorial, o qual, em interação com uma ou mais barreiras, pode obstruir sua participação plena e efetiva na sociedade em igualdade de condições com as demais pessoas (BRASIL, 2015b).

Na conceituação de pessoa com deficiência existente na Convenção sobre os Direitos da Pessoa com Deficiência e na legislação brasileira posterior à sua aprovação, conforme mencionado, percebe-se claramente a influência do denominado modelo social de deficiência (BERNARDES; ARAÚJO, 2012). Para esse modelo, a deficiência não está relacionada somente às restrições sensoriais, físicas, mentais ou motoras, mas às barreiras encontradas no convívio com a população e com as dificuldades na inclusão desses indivíduos na vida social (ARAÚJO, 1997). Por exemplo, a falta de mobilidade é resultado de um impedimento, mas um ambiente sem rampas transforma o impedimento em deficiência.

Assim, o conceito de deficiência está vinculado às restrições para o desempenho de atividades necessárias para a vida social. E, tornando-se possível a identificação das habilidades, deve-se levar em conta a complexidade da relação entre as habilidades, funcionalidades e o contexto social em que vive a pessoa (DINIZ; SQUINCA; MEDEIROS, 2007).

A terminologia científica ora apresentada é de suma relevância para que se dê maior atenção às pessoas com deficiência, pois o entendimento conceitual contribui para a elaboração de políticas públicas, respeitando as limitações e, ao mesmo tempo, valorizando as possibilidades desses indivíduos, beneficiando, assim, toda a sociedade (AMIRALIAN et al., 2000).

Destaca-se o entendimento de que as anomalias não devem ser interpretadas de forma homogênea, pois as potencialidades de cada um devem ser consideradas. 0 vínculo complexo entre o corpo, as habilidades e a sociedade aponta para uma verificação adequada do grau de deficiência somente a partir da realização de perícia biopsicossocial, com a avaliação da incapacidade e da funcionalidade por meio de interação dinâmica entre fatores ambientais e pessoais de cada pessoa com deficiência. Frente a isso, no próximo tópico, abordaremos o significado do termo políticas públicas, bem como analisa-se o Pronatec/ Viver sem Limite sob o ângulo dos destinatários, ou seja, as pessoas com deficiência. 


\subsection{POLITTICAS PÚBLICAS DE PROTEÇÃO ÀS PESSOAS COM DEFICIÊNCIA E O PRONATEC/VIVER SEM LIMITE}

As sociedades modernas têm como principal característica a diferenciação social. Isso significa que seus integrantes possuem atributos diferenciados (idade, sexo, religião, estado civil, escolaridade, renda, setor de atuação profissional, etc.), bem como valores, interesses e aspirações diferentes e desempenham papéis distintos no decorrer da sua existência. Tudo isso faz com que a vida em sociedade seja complexa e, frequentemente, envolva conflito: de opinião, de interesses, de valores, etc.

Nesse aspecto, para que a sociedade possa sobreviver e progredir, o conflito deve ser mantido dentro de limites administráveis. Para que isso ocorra é preciso a existência de políticas públicas.

Nas palavras de Secchi (2014, p. 01), as políticas públicas "tratam do conteúdo concreto e do conteúdo simbólico das decisões políticas, e do processo de construção e atuação dessas decisões". Aliado a isso, aduz que "política pública é uma diretriz para enfrentar um problema público". A política pública possui dois elementos preponderantes, quais sejam: intencionalidade pública e resposta a um problema público, isto é, a causa para o estabelecimento de uma política pública é o tratamento ou a resolução de um problema entendido como coletivamente relevante (SECCHI, 2014, p. 02).

No que tange à proteção das pessoas com deficiência, as políticas públicas destinam-se a assegurar e a promover, em condições de igualdade, o exercício dos direitos e das liberdades fundamentais da pessoa com deficiência, visando a sua inclusão social e à cidadania. Esse postulado legal contém um conjunto de orientações normativas que objetivam assegurar a esses sujeitos o pleno exercício dos direitos à vida, à saúde, à educação, à habilitação e à reabilitação profissional, à moradia, ao trabalho, à assistência social, à previdência social, à cultura, ao turismo, ao lazer, ao transporte, à mobilidade e à participação na vida pública e na política.

Não se deve negar que, nos últimos anos, o Brasil tem avançado na promoção dos direitos das pessoas com deficiência por meio de políticas públicas que buscam valorizar a pessoa como cidadã. Entretanto, percebem-se contradições entre as medidas contidas nas políticas públicas em relação aos interesses das pessoas com deficiência e às ações reais que são executadas. Na sociedade brasileira, verificamse ainda atitudes de descaso e de preconceito em relação aos direitos das pessoas com algum tipo de deficiência (FRAGA; SOUSA, 2009).

Nota-seque, embora exista todo umarcabouço jurídico dispondo sobre as políticas públicas direcionadas às pessoas com deficiência, a realidade do cotidiano dessas pessoas muitas vezes é preocupante.

Acerca da educação, percebe-se que a acessibilidade de grande parte das instituições de ensino impede a qualidade e a autonomia de vida de pessoas com deficiência, bem como muitos docentes ainda 
não estão preparados para superar adversidades em sala de aula, por exemplo, ter alunos com deficiência auditiva, visual, mental ou intelectual.

Neste aspecto, cabe asseverar que, de acordo com o Censo Demográfico de 2010, do Instituto Brasileiro de Geografia e Estatística (BRASIL, 2010a), o País possui 45.623 .910 pessoas com algum grau de dificuldade declarada, conforme o seguinte gráfico.

\section{Gráfico 1 - Grau de dificuldade declarada}

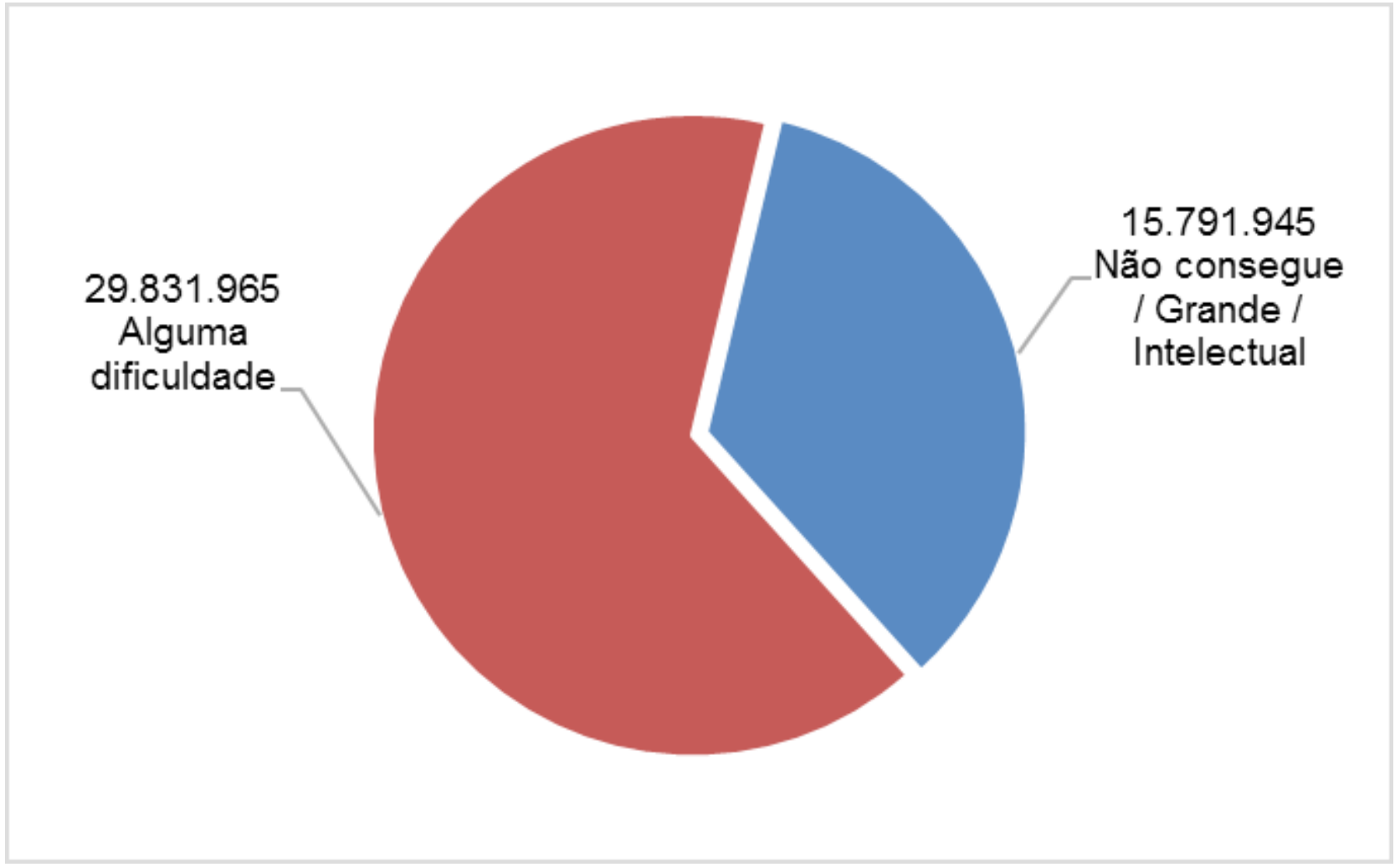

Fonte: elaborado pelo autor

Do total de 45.623.910 pessoas com algum grau de dificuldade declarada, 15.791.945 declararam ter grande dificuldade de desempenhar as atividades, ou até nem conseguir desempenhá-las em razão do grau ou da extensão da deficiência, ou por possuírem deficiência intelectual.

Dessas 15.791.945 pessoas, é preciso diminuir aquelas que possuem menos de 16 anos, que é a idade mínima para efetuar a matrícula nos cursos do Programa Nacional de Acesso ao Ensino Técnico e Emprego (Pronatec/Viver sem Limite), bem como as que possuem mais de 65 anos, por não fazerem 
parte da população economicamente ativa. Assim, o universo de pessoas com deficiência que formam o grupo que é objeto da política pública do Pronatec/Viver sem Limite fica reduzido para aproximadamente 11 milhões.

O Programa Nacional de Acesso ao Ensino Técnico e Emprego (Pronatec/Viver sem Limite) é uma política pública que tem por finalidade a qualificação profissional das pessoas com deficiência, por meio das ações de educação profissional e tecnológica desenvolvidas no âmbito do Pronatec, observadas as condições de acessibilidade e participação plena, tais como adequação de equipamentos, de materiais pedagógicos, de currículos e de estrutura física. E, por conseguinte, reduzir o problema coletivamente relevante da ausência de qualificação profissional das pessoas com deficiência.

Cabe asseverar que é necessária a organização ou a reorganização geral do ambiente educativo, sendo esse físico ou não, e do fazer docente, ou seja, as instituições regulares de ensino devem atender os alunos que apresentam qualquer tipo de deficiência (física, visual, mental, auditiva e intelectual) por meio da promoção das condições de acessibilidade, da capacitação de recursos humanos envolvidos, da flexibilização e da adaptação curricular.

Outrossim, é importante considerar que muitas pessoas com deficiências buscam a qualificação profissional como forma de construção de uma aprendizagem que se volte ao plano de garantia da cidadania e, paralelamente, de seus direitos. Como resultado, aumenta a consciência de que educação e trabalho devem andar juntos, assim, a qualificação profissional, nos dias de hoje, assume fundamental importância para a consolidação de políticas de inclusão social para as pessoas com deficiência.

A pesquisa abrange as pessoas com deficiência matriculadas nos cursos de qualificação profissional do Programa Nacional de Acesso ao Ensino Técnico e Emprego (Pronatec/Viver sem Limite) no período de 17/11/2011 a 31/12/2015 (BRASIL, 2016b), e a amostra foi composta de vinte e nove respondentes, distribuídas de acordo com o Gráfico 2. 


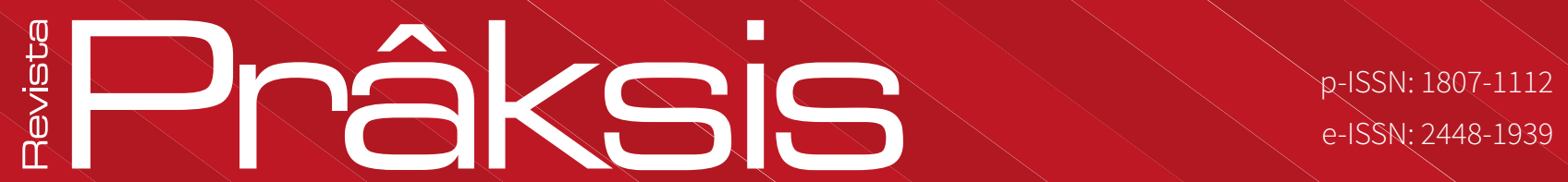

\section{Gráfico 2 - Número de entrevistas}

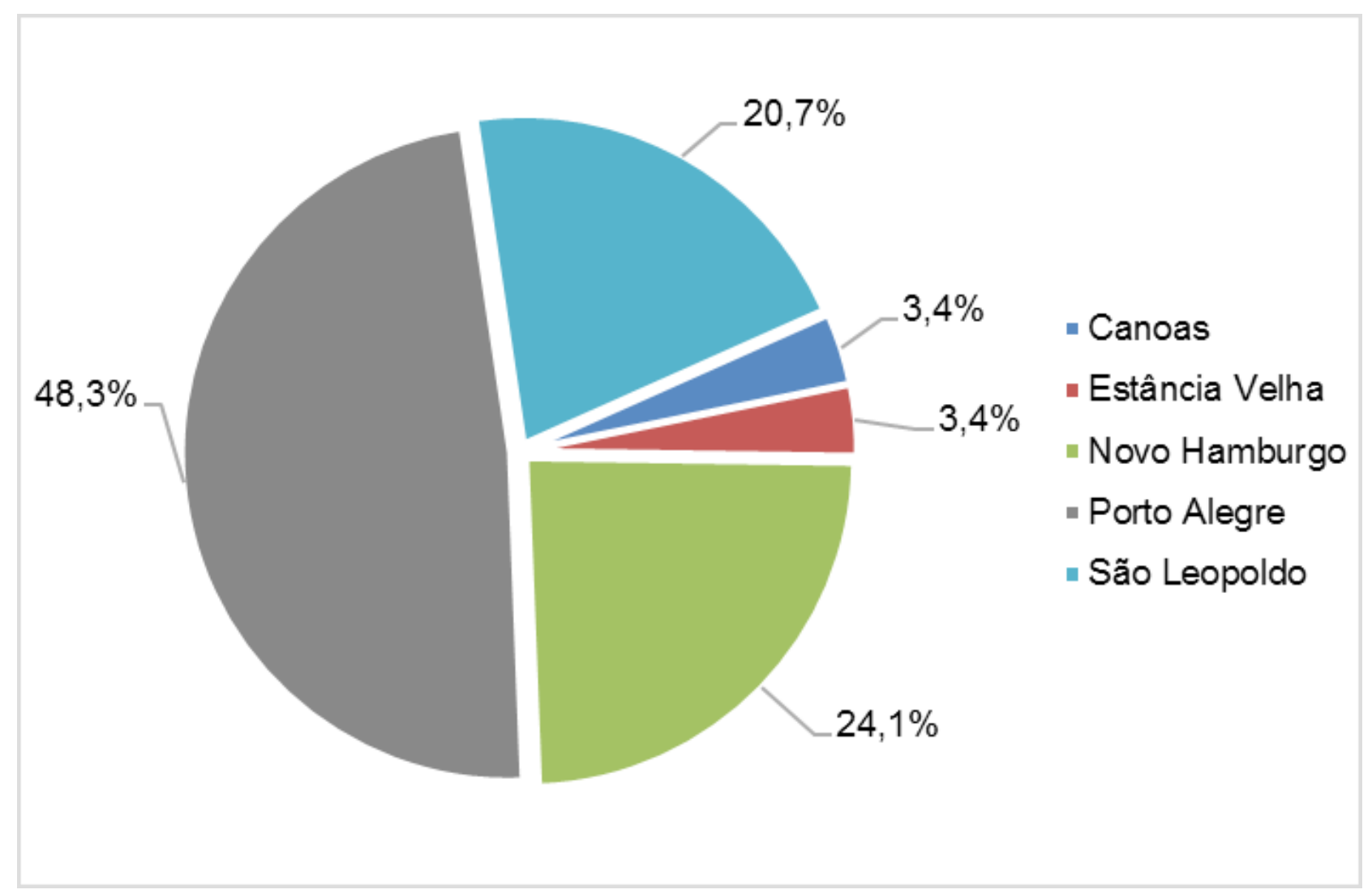

\section{Fonte: elaborado pelo autor}

De acordo com o gráfico acima, verifica-se que os entrevistados de Porto Alegre respondem por quase metade da amostra (48,3\%); os de Novo Hamburgo, por $24,1 \%$; os entrevistados de São Leopoldo, por $20,7 \%$; os de Estância Velha, por 3,4\%, e os de Canoas, também por 3,4\%.

Em relação à faixa etária dos entrevistados, destacam-se as seguintes, conforme Gráfico 3: de 28 a 32 anos (20,7\%); de 18 a 22 anos $(17,2 \%)$ e acima de 52 anos $(17,2 \%)$. 


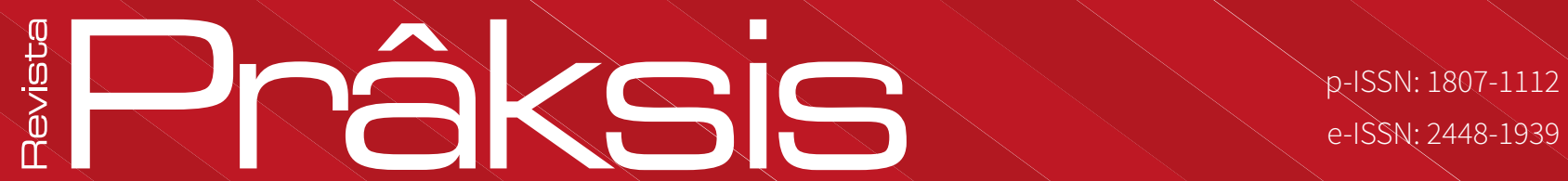

Gráfico 3 - Faixa etária dos respondentes

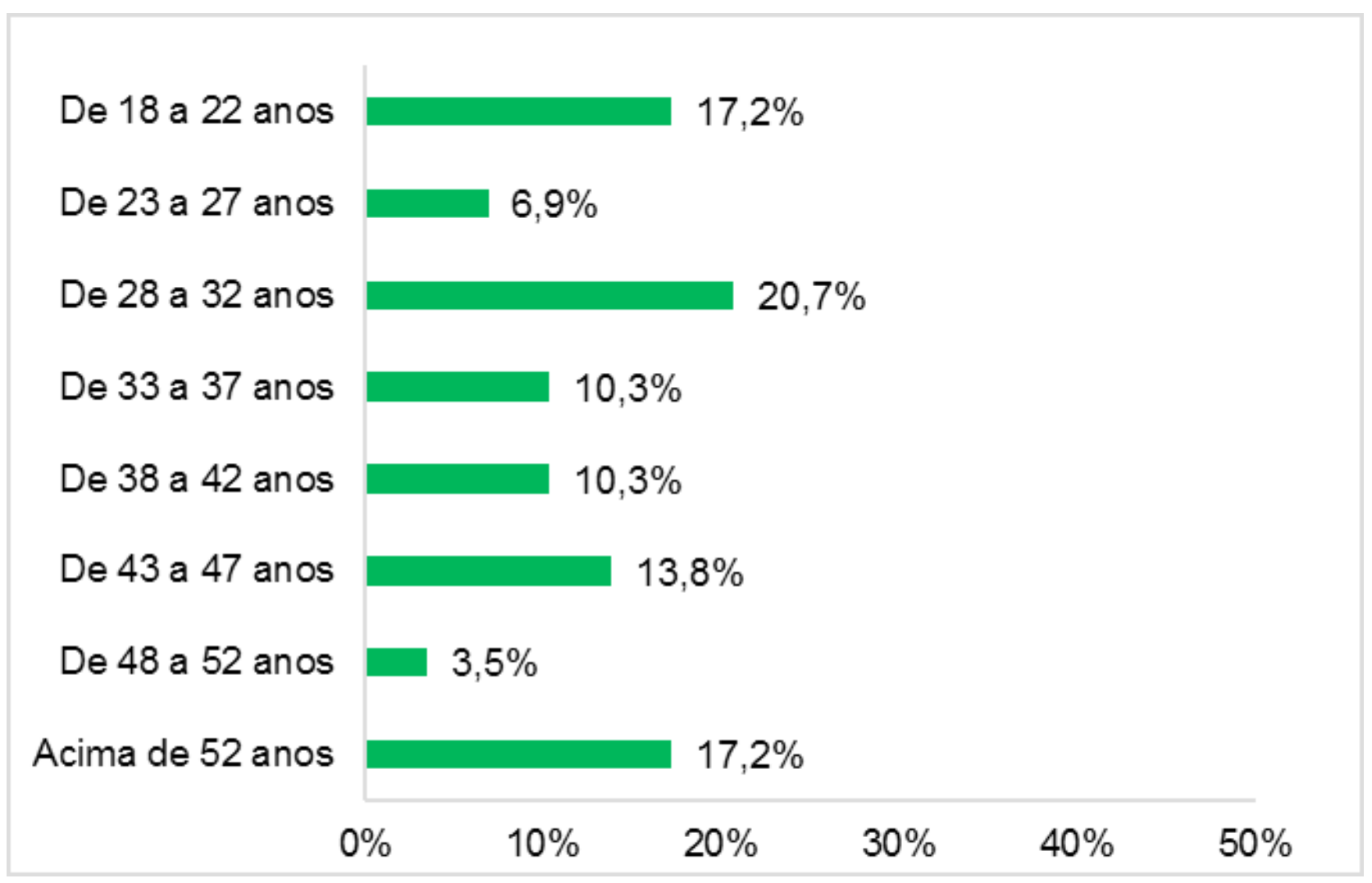

\section{Fonte: elaborado pelo autor}

Como podemos observar, os maiores percentuais se encontram nas faixas de 28 a 32 anos e de 18 a 22 anos, ou seja, parcela mais jovem da população que busca a qualificação profissional como facilitador da empregabilidade (cotas legais de pessoas com deficiência nas empresas). Além disso, o menor percentual de pessoas acima de 52 anos se justifica pelo fato de que, no Brasil, as pessoas com deficiência podem se aposentar por idade a partir dos 55 anos, se for mulher, e a partir dos 60 anos, se for homem, mediante a comprovação de no mínimo 180 contribuições mensais ao Regime Geral de Previdência Social.

De outro lado, cabe agora analisar a questão da deficiência na legislação (Estatuto da Pessoa com Deficiência). 0 trecho seguinte apresenta o conceito de pessoa com deficiência:

[...] Art. 20 Considera-se pessoa com deficiência aquela que tem impedimento de longo prazo de natureza física, mental, intelectual ou sensorial, o qual, em interação com uma ou mais barreiras, pode obstruir sua participação plena e efetiva na sociedade em igualdade de condições com as demais pessoas. 
§ 10 A avaliação da deficiência, quando necessária, será biopsicossocial, realizada por equipe multiprofissional e interdisciplinar e considerará:

I - os impedimentos nas funções e nas estruturas do corpo;

II - os fatores socioambientais, psicológicos e pessoais;

III - a limitação no desempenho de atividades; e

IV - a restrição de participação. [...] (DOC. 4, fl. 2, d. 2015).

É claro que esse conceito representou um enorme avanço no que diz respeito à inclusão social, pois, conforme mencionado anteriormente, a deficiência não é mais um atributo do indivíduo, mas o resultado gerado pela correlação entre os impedimentos da pessoa e o ambiente incapacitante.

Assim, não basta atestar que a pessoa tem um determinado impedimento e, por essa razão, tem maior dificuldade de realizar uma ou várias atividades, mas é necessário demonstrar que, em razão dessa dificuldade, há um prejuízo para a efetiva inclusão daquela pessoa na sociedade, retirando-Ihe oportunidades de participação plena e efetiva.

Cabe esclarecer que, embora o conceito antes referido não mencione, também se considera pessoa com deficiência o indivíduo reabilitado, ou seja, aquele que passou por processo de reabilitação junto ao Instituto Nacional de Seguro Social (INSS) com o objetivo de desenvolver potencialidades e aptidões físicas, cognitivas, sensoriais, entre outras, para a conquista da sua autonomia.

Por conseguinte, no término desse processo, o Instituto Nacional de Seguro Social (INSS) fornece ao indivíduo um Certificado de Reabilitação Profissional. Independentemente do tipo de deficiência à época de reabilitação, esta é válida e não é necessário nenhum laudo biopsicossocial realizado por equipe multiprofissional e interdisciplinar.

Essa situação é importante para esclarecer que a empresa, ao contratar uma pessoa com deficiência, deve realizar um laudo caracterizador de deficiência, no qual serão indicadas a natureza da deficiência, a respectiva descrição e eventuais restrições.

Nesse aspecto, esclarece-se que os dados públicos relativos às pessoas com deficiência constantes do Programa de Disseminação das Estatísticas do Trabalho (PDET) (BRASIL, 2017a) e oriundos de dois registros administrativos, a Relação Anual de Informações Sociais (RAIS) (BRASIL, 2015a) e o Cadastro Geral de Empregados e Desempregados (CAGED), (BRASIL, 2017b) ambos do Ministério do Trabalho, advêm de informações prestadas pelas empresas com base no laudo caracterizador de avaliação, conforme mencionado.

Sob essa ótica, salienta-se que os dados referentes às pessoas com deficiência e/ou aos tipos de deficiências constantes no Censo Demográfico de 2010 (IBGE, 2010) foram tabulados a partir do boletim de recenseamento que foi respondido por um membro de cada agregado familiar no momento da visita 
do recenseador ao seu domicílio, ou seja, o Instituto Brasileiro de Geografia e Estatística (IBGE) não exigiu documentos que comprovassem a veracidade das informações prestadas.

Quanto à presente pesquisa, informa-se que também não foi solicitado laudo caracterizador de deficiência, pois, conforme citado, a coleta de dados foi realizada por meio de entrevista semiestruturada, que foi respondida pela própria pessoa com deficiência ou, na impossibilidade, pelo pai, pela mãe, pelo esposo, pela esposa, pelo companheiro, pela companheira ou por outro parente. Entretanto, no início de cada entrevista, frisou-se que era muito importante que o entrevistado respondesse corretamente ao questionário.

Em relação à natureza da deficiência dos integrantes da amostra, fez-se a seguinte pergunta: "Qual o seu tipo de deficiência?", conforme segue no Gráfico 4.

\section{Gráfico 4 - Qual o seu tipo de deficiência?}

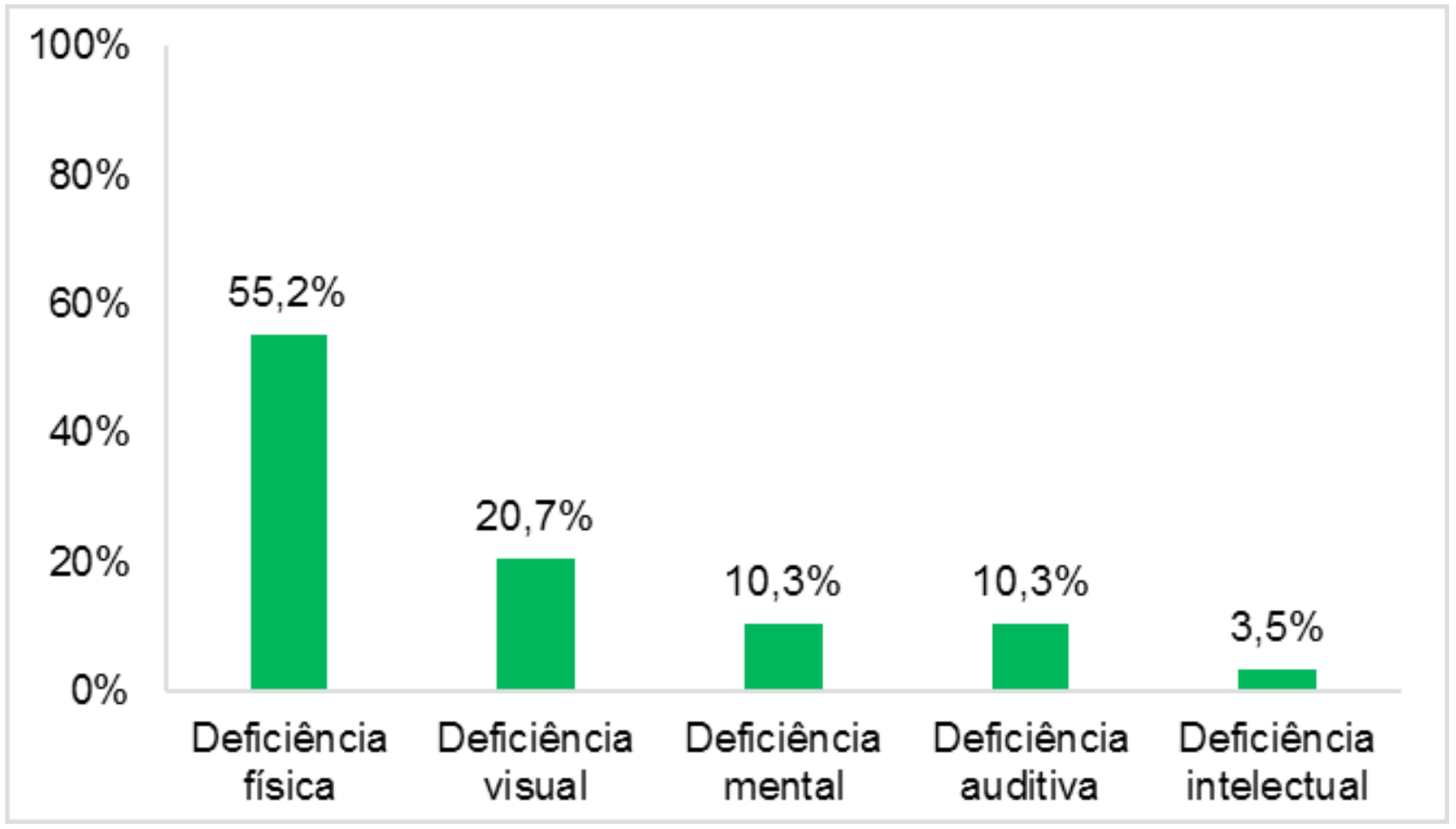

Fonte: elaborado pelo autor 
Da análise do Gráfico 4, nota-se que a maioria dos respondentes informou ter deficiência física, ou seja, 55,2\%; 20,7\% informaram ter deficiência visual; 10,3\%, deficiência mental; 10,3\% informaram ter deficiência auditiva, e 3,5\%, deficiência intelectual.

Esse percentual de pessoas com deficiência de natureza física é um pouco maior que o das pessoas com deficiência incluídas nas cotas legais (artigo 93 da Lei n 8.213/1991) e que consta na Relação Anual de Informações Sociais - RAIS (BRASIL, 2015a), em que, do total de 403.255 pessoas com deficiência, $50,5 \%$ são deficientes físicos.

Tal hipótese é atestada a partir das respostas dos próprios destinatários da política pública, pois para os respondentes que trabalharam ou estavam trabalhando com a Carteira de Trabalho e Previdência Social (CTPS) assinada (mercado formal de trabalho), perguntou-se: qual o seu tipo de deficiência? Verificam-se os resultados na Tabela 1.

\section{Tabela 1 - Tipos de deficiência X trabalha (trabalhou) com a Carteira de Trabalho e Previdência Social (CTPS) assinada}

\begin{tabular}{l|l}
\hline Tipo de deficiência & Trabalha (trabalhou) com a Carteira de Trabalho e Previdência Social (CTPS) assinada \\
\hline Deficiência física & $52,2 \%$ \\
Deficiência visual & $21,7 \%$ \\
Deficiência mental & $8,7 \%$ \\
Deficiência auditiva & $13,1 \%$ \\
Deficiência intelectual & $4,3 \%$ \\
\hline Total & $100 \%$ \\
\hline
\end{tabular}

\section{Fonte: elaborado pelo autor}

Da análise da Tabela 1, verifica-se que 52,2\% dos respondentes que trabalharam ou estavam trabalhando com a Carteira de Trabalho e Previdência Social (CTPS) assinada são deficientes físicos.

Nesse contexto, o Estatuto da Pessoa com Deficiência assim prevê: "[...] Art. 34. A pessoa com deficiência tem direito ao trabalho [...] em igualdade de oportunidades com as demais pessoas. [...]" (DOC. 4, fl. 4, d. 2015).

Portanto, no que se refere ao tipo de deficiência, percebe-se que, muitos empregadores contratam pessoas com deficiência de natureza física, geralmente, por necessitarem poucas adaptações na estrutura física da empresa (acessibilidade arquitetônica e instrumental). 
Quanto à descrição da deficiência física, o Decreto n 3.298, de 20/12/1999, conceitua:

[...] I - deficiência física - alteração completa ou parcial de um ou mais segmentos do corpo humano, acarretando o comprometimento da função física, apresentando-se sob a forma de paraplegia, paraparesia, monoplegia, monoparesia, tetraplegia, tetraparesia, triplegia, triparesia, hemiplegia, hemiparesia, ostomia, amputação ou ausência de membro, paralisia cerebral, nanismo, membros com deformidade congênita ou adquirida, exceto as deformidades estéticas e as que não produzam dificuldades para 0 desempenho de funções; [...] (DOC. 4, fl. 1, d. 1999). (Grifou-se)

Nessa descrição, não estão previstas expressamente as alterações articulares ou da coluna vertebral, importantes e que limitam a amplitude de movimentos e são sequelas definitivas, bem como as alterações permanentes do aparelho fonatório (da fala) com importante prejuízo na comunicação, porém, devem ser consideradas deficiências físicas. Em relação a isso, esclarece-se que, dos dezesseis respondentes que declararam ser pessoas com deficiência física, dois informaram possuir alterações na coluna vertebral que dificultam os movimentos (portanto, enquadram-se na primeira situação), e outro informou que teve câncer nas cordas vocais e, por isso, tem dificuldades de falar (por conseguinte, enquadra-se na segunda situação).

O Decreto n³.298, de 20/12/1999 (DOC. 4, fl. 1, d. 1999), também exclui as deformidades estéticas. Todavia, como se relatou anteriormente, a deficiência é gerada pela correlação entre os impedimentos da pessoa e o ambiente incapacitante. Dessa forma, não é possível excluir as pessoas que são estigmatizadas por alguma deformidade, já que a barreira atitudinal ainda é uma das mais significativas no País. Sendo assim, pessoas que são excluídas do trabalho e da vida social por algum estigma estético devem ser consideradas pessoas com deficiência física.

Assim, chama a atenção o percentual de $20,7 \%$ dos respondentes com deficiência de natureza visual. Isso demonstra que essas pessoas buscam a qualificação profissional como forma de viabilizar mais oportunidades de inclusão no ambiente laboral, tendo em vista que apenas 10,4\% do total de pessoas com deficiência incluídas nas cotas do artigo 93 da Lei nº 8.213/1991 são deficientes visuais (BRASIL, 2015a).

O parágrafo terceiro do artigo 34 do Estatuto da Pessoa com Deficiência, por sua vez, dispõe: "[...] § 30 É vedada restrição ao trabalho da pessoa com deficiência e qualquer discriminação em razão de sua condição [...] (DOC. 2, fl. 4, d. 2015). Esse dispositivo, porém, é deixado de lado, tendo em vista que as pessoas com deficiência visual sofrem restrições no que se refere às contratações por parte das empresas.

Aliás, o Decreto n³.298, de 20/12/1999, apresenta a caracterização da deficiência de natureza visual: 
[...] III - deficiência visual - cegueira, na qual a acuidade visual é igual ou menor que 0,05 no melhor olho, com a melhor correção óptica; a baixa visão, que significa acuidade visual entre 0,3 e 0,05 no melhor olho, com a melhor correção óptica; os casos nos quais a somatória da medida do campo visual em ambos os olhos for igual ou menor que 60o; ou a ocorrência simultânea de quaisquer das condições anteriores; [...] (DOC. 4, fl. 1, d. 1999).

Essa concepção é restritiva e excludente, pois opera uma discriminação ao não abranger as pessoas que apresentam visão monocular ou estrabismo . Entretanto, entende-se que essas pessoas devem ser consideradas como deficientes visuais. Inclusive, na presente pesquisa, das seis pessoas que declararam ter deficiência visual, três informaram ter baixa visão, e três informaram apresentar visão monocular.

Repisa-se, por derradeiro, que as caracterizações das deficiências não podem ser restritivas, tendo em vista que as deficiências são resultantes da interação entre impedimentos (distúrbios, doenças e lesões), fatores contextuais ambientais (ausência de acessibilidade arquitetônica, de comunicação, preconceitos, etc.) e pessoais (como gênero, raça, condições sociais, escolaridade, qualificação profissional).

\section{CONSIDERAÇÕES FINAIS}

No presente artigo, analisou-se a política pública (Pronatec/Viver sem Limite) instituída pelo governo federal, especificamente, em relação aos municípios de Canoas, Estância Velha, Novo Hamburgo, Porto Alegre e São Leopoldo, no período de 17/11/2011 a 31/12/2015, que tem como finalidade a qualificação profissional das pessoas com deficiência por meio das ações de educação profissional e tecnológica desenvolvidas no âmbito do Pronatec, observadas as condições de acessibilidade e participação plena, tais como adequação de equipamentos, de materiais pedagógicos, de currículos e de estrutura física.

Demonstramos que, ao longo do tempo, existiram alterações de concepções no que se refere à deficiência, e as diversas mudanças de denominações refletem o empenho dos movimentos sociais para rechaçar a noção de "menos-valia" sobre a deficiência, tendo em vista que, inclusive no Brasil, já foram utilizados termos como "aleijados", "incapazes", "inválidos".

Observamos também que a grande mudança de paradigmas ocorreu a partir da Convenção Internacional sobre os Direitos da Pessoa com Deficiência, quando passou a se entender que a pessoa com deficiência é aquela que tem impedimentos de longo prazo de natureza física, mental, intelectual ou sensorial, os quais, em interação com diversas barreiras, podem obstruir sua participação plena e efetiva na sociedade em igualdade de condições com as demais pessoas.

Nesse aspecto, verificou-se que a deficiência é provocada pela interação dos impedimentos com as barreiras sociais, ou seja, com os diversos fatores culturais, econômicos, tecnológicos, arquitetônicos, 
entre outros, de forma a gerar uma impossibilidade de efetiva participação do indivíduo deficiente na sociedade.

Constatou-se que as anomalias não devem ser interpretadas de forma homogênea, pois as potencialidades de cada um devem ser consideradas. Desta forma, faz-se necessária a realização de perícia biopsicosocial, com a avaliação da incapacidade e da funcionalidade por meio de interação dinâmica entre fatores ambientais e pessoais de cada indivíduo, para verificar o respectivo grau de deficiência, sendo que tal situação contribuirá para a implementação das políticas públicas relacionadas às pessoas com deficiência, de maneira consistente.

Verificou-se que o Programa Nacional de Acesso ao Ensino Técnico e Emprego (Pronatec/Viver sem Limite) tem por finalidade a qualificação profissional das pessoas com deficiência. Sob esse prisma, é inegavelmente uma política pública, pois busca reduzir o problema coletivamente relevante da ausência de qualificação profissional dessas pessoas.

Contudo, demonstrou-se a hipótese inicialmente apresentada, tendo em vista que 55,2\% dos respondentes informou ter deficiência física, ou seja, muito embora a deficiência possa se apresentar na modalidade física, visual, mental, auditiva e intelectual, a maioria das pessoas com deficiência matriculadas no Programa Nacional de Acesso ao Ensino Técnico e Emprego (Pronatec/Viver sem Limite) apresentam deficiência física.

Constatou-se que esse percentual de pessoas com deficiência de natureza física é superior ao das pessoas com deficiência incluídas nas cotas legais (artigo 93 da Lei $n^{\circ} 8.213 / 1991$ ) e que constam na Relação Anual de Informações Sociais (BRASIL, 2015a), em que, do total de 403.255 pessoas com deficiência, 50,5\% são deficientes físicos.

No que se refere ao tipo de deficiência, percebe-se que muitos empregadores contratam pessoas com deficiência de natureza física, geralmente, por necessitarem poucas adaptações na estrutura física da empresa (acessibilidade arquitetônica e instrumental).

Por derradeiro, verificou-se que as caracterizações das deficiências não podem ser restritivas, tendo em vista que as deficiências são resultantes da interação entre impedimentos (distúrbios, doenças e lesões), fatores contextuais ambientais (ausência de acessibilidade arquitetônica, de comunicação, preconceitos, etc.) e pessoais (como gênero, raça, condições sociais, escolaridade, qualificação profissional). 


\section{REFERÊNCIAS}

AMIRALIAN, M. et al. Conceituando deficiência. Revista de Saúde Pública, São Paulo, v. 1, n. 34, p. 97103, fev. 2000.

ARAUJO, L. A proteção constitucional das pessoas portadoras de deficiência. Brasília: Corde, 1997, p. 148.

BERNARDES, L.; ARAÚJO, T. Deficiência, políticas públicas e bioética: percepção de gestores públicos e conselheiros de direitos. Ciência \& Saúde Coletiva, Rio de Janeiro, v. 17, n. 9, p. 2435-2445, set. 2012.

BOUCINHAS FILHO, J. Ações afirmativas e inserção de pessoas portadoras de deficiência no mercado de trabalho. Revista da Faculdade de Direito da Universidade de São Paulo, São Paulo, v. 100, p. 493523, jan./dez. 2005.

BRASIL. MINISTÉRIO DA EDUCAÇÃO. PRESIDÊNCIA DA REPÚBLICA. Lei n 13.146. 2015b. Disponível em: <http://www4.planalto.gov.br/legislacao>. Acesso em: 15 jan. 2017.

BRASIL. MINISTÉRIO DO TRABALHO. Cadastro Geral de Empregados e Desempregados (CAGED). $2017 \mathrm{~b}$. Disponível em: <http://pdet.mte.gov.br/caged>. Acesso em: 15 jan. 2017.

BRASIL. MINISTÉRIO DO TRABALHO. Programa De Disseminação Das Estatísticas Do Trabalho (PDET). 2017a. Disponivel em: <http://pdet.mte.gov.br/rais?view=default>. Acesso em: 15 jan. 2017.

BRASIL. MINISTÉRIO DO TRABALHO. Relação Anual de Informações Sociais (RAIS). (2015a). Disponível em: <http://pdet.mte.gov.br/rais?view=default>. Acesso em: 15 jan. 2017.

BRASIL. Presidência da república. Decreto Legislativo n 186. 2008a. Disponível em: <http://www4. planalto.gov.br/legislacao>. Acesso em: 15 jan. 2017.

BRASIL. Presidência da república. Decreto n 3.298. 1999. Disponível em: <http://www.planalto.gov.br/ ccivil_03/decreto/D3298.htm>. Acesso em: 15 jan. 2017.

BRASIL. Presidência da república. Decreto n 7.612. 2011. Disponível em: <http://www4.planalto.gov.br/ legislacao>. Acesso em: 15 jan. 2017.

BRASIL. Presidência da república. Lei nº 7.853. 1989. Disponivel em: <http://www.planalto.gov.br/ ccivil_03/leis/L7853.htm>. Acesso em: 15 jan. 2017. 
BRASIL. Presidência da república. Lei n 8.742. 1993. Disponível em: <http://www4.planalto.gov.br/ legislacao>. Acesso em: 15 jan. 2017.

BRASIL. Sistema Nacional de Informações da Educação Profissional e Tecnológica (Sistec). 2016. Disponivel em: <http://sitesistec.mec.gov.br>. Acesso em: 15 jan. 2017.

BUBLITZ, M. Conceito de pessoa com deficiência: comentário à ADPF 182 do STF. Revista da AJURIS, Porto Alegre, v. 39, n. 127, p. 353-369, set. 2012.

DINIZ, D.; SQUINCA, F.; MEDEIROS, M. Qual deficiência?: perícia médica e assistência social no Brasil. Cadernos de Saúde Pública, Rio de Janeiro, v. 23, n. 11, p. 2589-2596, dez. 2007.

FÁVERO, E. Direito das pessoas com deficiência: garantia de igualdade na diversidade. WVA, 2007, 343 p.

LENZA, P. Direito Previdenciário Esquematizado. São Paulo: Saraiva, 2012, p. 189-190.

INSTITUTO BRASILEIRO DE GEOGRAFIA E ESTATÍSTICA (IBGE). Censo demográfico. 2010. Disponível em: <http://www.ibge.gov.br/home/estatistica/populacao/censo2010/default.shtm>. Acesso em: 15 jan. 2017.

MAIA, M. Novo conceito de pessoa com deficiência e proibição do retrocesso. Revista da AGU, Brasília, v. 12, n. 37, p. 289-306, set. 2013.

MARTA, T. Exclusão Social X Vida Digna: Direito ao trabalho das pessoas com deficiência, uma questão de princípios. Argumentia Journal Law, Jacarezinho, v. 12, n. 12, p. 75-98, fev. 2013.

OLIVEIRA, M.; DE SOUSA, A. Políticas públicas para pessoas com deficiência no Brasil: o desafio da inclusão social. Revista Eletrônica de Enfermagem, Goiânia, v. 11, n. 2, mai. 2009. Disponível em: <https://www.fen.ufg.br/fen_revista/v11/n2/v11n2a25.htm>. Acesso em: 15 jan. 2017.

ORGANIZAÇÃO DAS NAÇÕES UNIDAS. Convenção Internacional sobre os Direitos das Pessoas com Deficiência. Nova York, 2007.

SECCHI, L. Políticas públicas: conceitos, esquemas de análise, casos práticos. São Paulo: Cengage Learning, 2014, $188 \mathrm{p}$.

SILVA, C. Panorama histórico dos direitos sociais e a pessoa portadora de deficiência. Juris Síntese IOB, v. 17, n. 201, p. 39-58, mar. 2006. 